conclusions regarding the ineffectiveness of antipyretic agents in the prevention of FS. Aspirin and acetaminophen fail to retard the rate of temperature rise induced by radiotherm diathermy in animals, and large toxic doses of aspirin lower the threshold convulsive temperature and exacerbate experimental FS. (Millichap, 1968). Antipyretics in therapeutic doses facilitate heat loss and relieve discomfort associated with fever but do not retard temperature rise and have no proven anticonvulsant effect. Heat production is not inhibited by salicylates, but heat dissipation is augmented by increased peripheral blood flow and sweating. (Goodman LS, Gilman A. Eds. The Pharmacological Basis of Therapeutics, $5^{\text {th }}$ ed, New York, Macmillan, 1975;p327). Numerous studies have shown comparable antipyretic efficacy for aspirin and acetaminophen (ASAP) in febrile children (Wilson JT. In: Febrile Seizures, eds Nelson KB, Ellenberg JH, New York, Raven Press, 1981;pp231-239). Maximum antipyresis for rectal suppositories of ASAP occurs at 2.5 to 4 hours, and efficacy of both oral and rectal ASAP is related to dose and plasma level. Addition of tepid water sponging increases maximum antipyresis of ASAP, but does not shorten time of onset of antipyresis. Ineffectiveness of intermittent antipyretic treatment in the prevention of febrile seizures is sometimes linked to failure to determine plasma levels, poor compliance, and difficulty in recognizing the onset of the febrile illness. Further controlled studies may be indicated.

Ibuprofen was significantly superior to acetaminophen in antipyretic efficacy, in a randomized, multiple dose, double-blind study comparing ibuprofen $(5 \mathrm{mg} / \mathrm{kg})$ and acetaminophen $(10 \mathrm{mg} / \mathrm{kg})$ in 70 outpatients (mean age, 2.1 years) at risk for febrile seizure recurrence. Antipyretics were administered every 6 hours for 1 to 3 days during fever, and rectal temperatures were recorded at $0,2,4,6,12$, and 24 hours after the first dose. Ibuprofen reduced fever $0.5^{\circ} \mathrm{C}$ more than acetaminophen at 4 hours, and in a crossover trial, the differences in temperature reduction were 0.66 and $0.36^{\circ} \mathrm{C}$, in favor of ibuprofen. (Van Esch A et al. Arch Pediatr Adolesc Med 1995;149:632-637). An anticonvulsant effect of the antipyretic was not established.

Dr Sheila Wallace, in memoriam. Febrile seizures were a major interest of Dr Wallace, Consultant Paediatric Neurologist, University Hospital of Wales, Cardiff. Dr Wallace died on December 25, 2002. An obituary, written by Dr John BP Stephenson, is published in Brain Dev Aug 2003;25:299-300, and is available online July 2, 2003. Among other articles, Dr Wallace contributed two papers to the symposium on Febrile Seizures, edited by Nelson KB \& Ellenberg JH, New York, Raven Press, 1981. These pertained to "Prevention of recurrent febrile seizures using continuous prophylaxis: sodium valproate compared with phenobarbital" and "Supportive family management."

\title{
GENETICS OF FEBRILE SEIZURES
}

The genetics of febrile seizures (FS) are reviewed by members of the Department of Pediatrics, Fukuoka University; Department of Neuropsychiatry, Hirosaki University, Japan; and National Institutes of Health, Research Triangle Park, NC, USA. Several genetic loci for FS have been mapped, but the exact molecular mechanism is unknown. Mutations have been found in genes encoding $\mathrm{Na}^{+}$channel subunits and the g2 subunit of gamma amino-butyric acid $(\mathrm{GABA})_{\mathrm{A}}$ receptors. These channels are associated with 
autosomal dominant epilepsy with FS plus, generalized epilepsy with FS plus, and with severe myoclonic epilepsy in infancy that often begins with a prolonged FS. Various $\mathrm{Na}^{+}$ channels and $\mathrm{GABA}_{\mathrm{A}}$ receptors in the brain are probably involved in the pathogenesis of frequent FS and also, in simple FS. Genetic linkage analyses have mapped FS to four loci, FEB1,2,3 and 4, in chromosomes 8q13, 19p, 2q23-q24, and 5q14-q15, respectively. (Hirose S, Mohney RP, Okada M et al. The genetics of febrile seizures and related epilepsy syndromes. Brain Dev August 2003;25:304-312). (Respond: Dr Shinichi Hirose, Department of Pediatrics, School of Medicine, Fukuoka University, 45-1, 7-chome Nanakuma, Jonanku, Fukuoka 814-0180, Japan).

COMMENT. The determination of the molecular genetic mechanism of FS may lead to more specific therapies. FS occur with increased frequency among family members of patients with FS. Tsuboi (1977) reported $17 \%$ of parents and $22 \%$ of siblings of FS probands affected; $30 \%$ of siblings are affected if one parent has a history of FS (Hauser WA. In: Febrile Seizures. Ed by Nelson and Ellenberg, Raven Press, 1981). An analysis of 2,109 patients with FS reported between 1948 and 1963 in 12 different publications showed a mean familial incidence of $17 \%$ (range 2 to $58 \%$ ) (Millichap, 1968).

\section{GENETICS OF SEVERE MYOCLONIC EPILEPSY OF INFANCY}

The role of SCN1A gene mutations in the etiology of severe myoclonic epilepsy of infancy (SMEI) was investigated in 93 patients followed at the Hopital Saint Vincent de Paul, Paris, and other centers in France and Italy. SCNIA mutations occurred in 33 patients $(35 \%)$. Parents of three patients $(10 \%)$ who carried the inherited mutations were asymptomatic or had a milder form of epilepsy. Patients with the mutations had a greater frequency of unilateral motor seizures than those without and a more frequent family history of epilepsy. (Nabbout R, Gennaro E, Bernadina BD et al. Spectrum of SCN1A mutations in severe myoclonic epilepsy of infancy. Neurology June (2 of 2) 2003;60:19611967). (Reprints: Dr Rima Nabbout, Hopital Saint Vincent de Paul, Paris, France).

COMMENT. SMEI caused by SCN1A mutations is characterized by unilateral motor seizures, and $10 \%$ of cases are inherited from an asymptomatic or mildly affected parent. SMEI has a mean age of onset of 5 months, more than half the seizures are febrile, seizures are of all types, absence seizures with a myoclonic component are often triggered by photic stimulation, status epilepticus occurs in $75 \%$ and is often precipitated by fever, ataxia develops in $>80 \%$, psychomotor delay is common to all, and seizures are refractory to medication.

\section{EARLY ONSET ABSENCE EPILEPSY}

Neuropsychological evaluations, behavior patterns, and outcomes were studied in a retrospective analysis of 10 patients ( 7 girls, 3 boys) with onset of absence epilepsy before age 3 years, referred between 1986 and 2002 at Hopital Henri Gastaut, Marseille, and Hopital des Enfants, Toulouse, France. At $>2$ years of follow-up (range, 2 years 8 months to 9 years 4 months), only two had typical absences with good seizure control and good cognitive outcome. In the remaining 8 cases, 8 had cognitive delays and behavioral 